\title{
Evaluating biological containment strategies for pollen-mediated gene flow
}

\author{
Alexandra HÜSKEN*, Sabine PRESCHER and Joachim SCHIEMANN \\ Julius Kühn-Institute (JKI), Institute for Biosafety of Genetically Modified Plants, Erwin-Baur-Str. 27, 06484 Quedlinburg, Germany
}

\begin{abstract}
Several biological containment methods have been developed to reduce pollen dispersal; many of them only have a proof of concept in a model plant species. This review focuses on biological containment measures which were tested for their long-term efficiency at the greenhouse or field scale level, i.e. plastid transformation, transgene excission, cleistogamy and cytoplasmic male sterility (CMS). Pollen-mediated gene transfer in transplastomic tobacco could occur at very low frequencies if the predominant mode of inheritance is maternal. Transgene excision from tobacco pollen can be made highly efficient by coexpression of two recombinases. For cleistogamous oilseed rape it was shown that some flowers were partially open depending on genotypes, environment and recording dates. Reports on the stability of CMS in maize and sunflower indicated that there is a high variability for different genotypes under different environmental conditions and over successive years. But for both crop types some stable lines could be selected. These data demonstrate that the biological containment methods discussed are very promising for reducing gene flow but that no single containment strategy provides $100 \%$ reduction. However, the necessary efficiency of biological containment methods depends on the level of containment required. The containment level may need to be higher for safety purposes (e.g. production of special plant-made pharmaceuticals), while much lower containment levels may already be sufficient to reach coexistence goals. It is concluded that where pollen-mediated gene flow must be prevented altogether, combinations of complementary containment systems will be required.
\end{abstract}

Keywords: biological containment / biosafety / cleistogamy / cytoplasmic male sterility, plastid transformation / transgene excision

\section{INTRODUCTION}

The cultivation of genetically modified (GM) plants has been increasing over the past few years. In the context of biosafety of GM crops, gene flow is considered to be the most important factor. Gene flow indicates the movement of genes or genetic materials from one plant into another. Three possibilities for gene flow occur: pollen-mediated, seed-mediated and vegetative-propagule-mediated gene flow. Pollen-mediated gene flow will be primarily determined by the pollination biology of the plant species, outcrossing rates and pollen competition between donors and recipients. Physical or environmental conditions, such as distances between pollen donors and recipients, the strength and direction of wind, temperature and air humidity will also influence pollen-mediated gene flow to a great extent. Since pollination will cause hybridisation or further introgression into the environment, it could be a first, but important, step in the persistence and spread of

* Corresponding author: alexandra.huesken@jki.bund.de a transgene in wild populations and the environment ( $\mathrm{Lu}$, 2008). A range of possible environmental consequences (e.g., creation of new weeds and loss of genetic diversity in crop landraces and wild relatives) are conceivable and have been reviewed elsewhere (Conner et al., 2003; den Nijs et al., 2004; Peterson et al., 2000).

In its Scientific Opinion on Guidance for the risk assessment of GM plants used for non-food or non-feed purposes (EFSA, 2009) the EFSA Panel on Genetically Modified Organisms describes the importance of risk management systems, such as post-market environmental monitoring, standard production protocols/stewardship, or confinement strategies to reduce exposure to plants used for non-food or non-feed purposes. The risk assessment for these plants has to take into account the confinement measures when applied. In cases where gene flow from GM plants may result in adverse effects on human and animal health and the environment, it is essential to find efficient and reliable biological containment systems to prevent pollen-mediated gene flow during cultivation. The necessary efficiency of biological containment 
methods depends on the level of containment required. The containment level may need to be higher for safety purposes, while much lower containment levels may be sufficient to reach coexistence goals. A wide variety of biological containment strategies for pollen-mediated gene flow have been proposed (Bock and Timmis, 2008; Daniell, 2002; Gressel and Al-Ahmad, 2005; Murphy, 2007), either naturally occurring or engineered, such as plastid transformation, cleistogamy, male sterility, complete sterility by non-flowering, transgene excision or incompatible genomes. It should be noted here that the European Commission funded a Specific Targeted Research or Innovation Project in the Sixth Framework Programme to develop efficient and stable biological containment systems for GM plants (de Maagd and Boutilier, 2009). Most of the proposed strategies did not move beyond a proof of principle in model plants and were not studied for their use as a biological containment strategy in practice. However, there is a need to ensure that instabilities do not limit or even prevent such strategies and that their long-term effectiveness under various environmental and agricultural conditions has been tested. Here, we review the most promising containment methods for pollen-mediated gene flow, which were assessed for their stability and reliability at a greenhouse (transplastomic tobacco and transgene excision in tobacco and Arabidopsis) and field scale level (cleistogamous oilseed rape and cytoplasmic male sterile maize and sunflower) published in peer-reviewed literature.

\section{BIOLOGICAL CONTAINMENT STRATEGIES FOR RESTRICTING POLLEN-MEDIATED GENE FLOW}

\section{Plastid transformation}

An acknowledged strategy for the prevention of pollenmediated gene flow is the targeting of the transgene to the chloroplast genome in species in which chloroplasts are generally maternally inherited (Birky, 1995; Bock and Khan, 2004; Dong and Wagner, 1994; Testolin and Cipriani, 1997). In addition to maternal inheritance, the transplastomic approach offers a number of advantages including high-level transgene expression (DeCosa et al., 2001); multi-gene engineering in a single transformation event (Quesada-Vargas et al., 2005; Ruiz and Daniell, 2005); lack of gene silencing, position effect and pleiotropic effects (Daniell et al., 2005; Grevich and Daniell, 2005).

Plastid transformation has been achieved in many important crops, including tobacco, soybean, potato, tomato, cotton, as well in minor species, such as lettuce, petunia and Lesquerella fendleri (Brassicaceae, cultivated for oil production) and in non-crop systems, such as the alga Clamydomonas reinhardtii (Murphy, 2007). The cultivation of transplastomic GM cultivars revealed some disadvantages in respect to containment: Although maternal inheritance is widely assumed to be the general rule in most angiosperms, rare pollen-mediated gene transfer has been detected in a number of cases (Murphy, 2007). Rare, but possible, transmission of plastid DNA via pollen (Cummins, 1998; Lu, 2003; Wang et al., 2004), even with very low levels of paternal gene transfer, may be sufficient for the escape and spread of a transgene (Haygood et al., 2004). It is also conceivable that transplastomic GM crops could be fertilized by pollen from other plants resulting in hybridisation (Dunwell and Ford, 2005; Lu, 2003,2008 ). The resulting hybrid seeds could disperse in the environment. Furthermore, chloroplast DNA may be transferred to the nucleus at low frequencies and be integrated into the nuclear genome (Haygood et al., 2004; Medgyesy et al., 1980). In this case, the transgene is inherited biparentally resulting in a failure of the containment strategy (Sheppard et al., 2008; Stegemann and Bock, 2006).

Several studies assessed the rate of pollen-mediated plastomic or chloroplast gene transfer. Wang et al. (2004) found in Setaria italica (foxtail bristlegrass, often cultivated in Asia) a paternal inheritance of $0.03 \%$ of all seedlings. The rate of pollen-mediated gene transfer in the ornamental Petunia hybrida was even $2 \%$ of all progenies (Derepas and Dulieu, 1992). Azhagiri and Maliga (2007) reported a low frequency of $3.9 \times 10^{-5}$ of transmission of paternal plastids in Arabidopsis thaliana. In a field study, Allainguillaume et al. (2009) found only modest crop chloroplast presence in wild Brassica oleracea and in weedy $B$. rapa, but a surprisingly high incidence in sympatric (but not in allopatric) riverside $B$. rapa populations. Several studies focussed on the pollen-mediated gene transfer in tobacco (Avni and Edelmann, 1991; Medgysey et al., 1986; Svab and Maliga, 2007). Ruf et al. (2007) assessed the extent to which plastid transformation technology can be used as a biological mitigation technique in tobacco. They described an experimental system facilitating stringent selection for occasional paternal plastid transmission. In a large screen, they detected low-level paternal inheritance of transgenic plastids in tobacco. Whereas the frequency of transmission into the cotyledons of $\mathrm{F} 1$ seedlings was $1.58 \times 10^{-5}$ (on $100 \%$ cross fertilization), transmission into shoot apical meristems was significantly lower $\left(2.86 \times 10^{-6}\right)$. The authors concluded that plastid transformation provides an effective tool to increase the biosafety of transgenic plants. Moreover, the frequency of pollen-mediated gene transfer under lab conditions (stringent selection) is probably much higher than under field conditions. It can be summarized that more field scale research is needed in this promising area to perfect this approach for biological containment of transgenes. 


\section{Transgene excision}

Pollen-mediated gene flow can be effectively eliminated by incorporation of a transgene excision system into the process of pollen formation (Mlynárová et al., 2006). Transgene excision resembles the removal of a transgene construct or parts of it from the plant genome by means of recombinase enzymes acting on two target sites flanking the DNA to be excised. The best-known recombination systems are CRE/lox from bacteriophage P1, $\mathrm{FLP} /$ frt from Saccharomyces cerevisiae and $\mathrm{R} / R S$ from Zygosaccharomyces rouxii (Gidoni et al., 2008). Most plant applications use the CRE/lox system. Transgene excision has been demonstrated in many crops, including tobacco, Arabidopsis, tomato, potato, soybean, wheat and maize. Recombinase activity can be induced by heat or chemical treatments or by the use of a developmentally regulated promoter (Gidoni et al., 2008).

Promoter-driven removal of transgenic DNA during pollen development results in male gametes that do not carry the transgene. Experimental data are limited to tobacco (Nicotiana tabacum) and Arabidopsis focusing on the removal of a selectable marker from the construct in a process known as auto-excision (Luo et al., 2007; Mlynárová et al., 2006). However, these results can be extrapolated to approaches intended for biological containment of the whole construct before or during pollen development. Excision of transgenes regulated in the pollen from Arabidopsis and tobacco can be highly efficient (Mlynárová et al., 2006) and was achieved by using the tobacco NTM19 microspore-specific promoter. Activation of the promoter during pollen formation resulted in recombinase-mediated auto-excision of all genetic material flanked by recombination sites in pollen only. As a result, all pollen of the GM plant should be wild type, except for the presence of a single recombination site. Small scale seed germination assays ( $n=100$ per line) of both tobacco and Arabidopsis seeds from backcrosses of single-event transgenic plants to wild type plants did not yield any kanamycin-resistant plants out of a total of 1800, indicating $100 \%$ transgene excision. Large scale assays ( $n=3000$ per line) on back-crossed tobacco lines yielded two non-excised plants out of a total of 15000 analyzed, corresponding to a failure rate of only $0.027 \%$ (Mlynárová et al., 2006). Luo et al. (2007) demonstrated an increased efficiency of transgene removal in tobacco when they have combined lox-frt recognition sites with pollen-specific expression of either Cre or FLP recombinases, compared to non-fused recognition sites of Cre/lox or FLP/frt recombination systems. The combination of Cre/lox and FLP/frt in a single construct resulted in $100 \%$ excision in approximately 25000 progeny of backcrosses to wild-type for six lines tested, which corresponds to less than $0.008 \%$ failure rate in tobacco (de Maagd and Boutilier, 2009). In addition, Luo et al. (2007) have demonstrated that the high excision efficiency remains stable in vegetatively propagated progeny plants.

In summary, the results presented show the feasibility of generating transgene-free pollen from transgenic plants under greenhouse conditions. However, if a recombinase is used to excise a transgene, the system must be working at an unexpectedly high efficiency to be an effective biological containment strategy at a field scale level. A calculation of Haygood et al. (2004) suggested that a failure rate of less than $10^{-3}$ is needed for large scale crop cultivation. In addition, it should be noted that the recombination systems used so far leave a single recombinase recognition site footprint (32 bp for lox). The resulting plants will still be considered transgenic and could be identified as such (Mlynárová et al., 2006).

\section{Cleistogamy}

Cleistogamy (CL), the trait of non-opening flowers, could be used to reduce pollen flow. Self-pollination and fertilisation take place within the closed bud and there is no release of pollen or exposure of the gynoecium to outcrossed pollen. CL is wide-spread among plants, but rare among crop species. Examples of crop species that exhibit some degree of cleistogamy are barley (Kurauchi et al., 1994; Turuspekov et al., 2004), soybean (Benitez et al., 2010; Miyashita et al., 1999) and rice (Connor, 1979; Hoshikawa, 1993).

Transgene containment by the use of CL appears to be easy to apply for some crop species, but it is not practical for all crops ( $\mathrm{Lu}, 2003)$. It is extremely difficult to create cleistogamous plants for allogamous crops such as maize (Dunwell and Ford, 2005). There is considerable evidence in the literature that suggests that cleistogamy in allogamous species is unlikely to be an evolutionary stable strategy (Diaz and MacNair, 1998). Only few examples exist of biocontainment research on cleistogamy in crops. To date cleistogamy is available for biological containment of pollen in rice (Yoshida et al., 2007) and oilseed rape (Leflon et al., 2009b). There is only limited information about the genetic control and regulatory mechanism of CL occurring in autogamous plant species. In rice, Nagao and Takahashi (1963) identified a CL rice mutant. They reported that the single recessive gene $d 7$ determined this mutant phenotype, and that the gene was possibly linked to the gene $d 6$ on chromosome 4 . Yoshida et al. (2007) identified another CL rice mutant harbouring a missense mutation. In this case, mutation of the class-B MADS-box gene, SUPERWOMEN-1 with altered lodicule identity, prevents flower opening. The reliability of this CL rice mutant was tested under field conditions in the central region of Japan. The CL trait was permanently stable and completely expressed; data about pollen dispersal were not collected. On the other 
side it was shown that in rice lines exhibiting cleistogamy, pollen-mediated gene flow occurs between feral and cultivated forms (Gealy, 2005; Gressel and Valverde, 2009). In oilseed rape CL plants do not occur in the genetic resources. A cleistogamous oilseed rape line was obtained by chemically induced mutagenesis of the cultivar 'Primor' at the National Institute for Agronomic Research in France (INRA Rennes; Patent FR 97 15768). Analysis of segregating phenotypic oilseed rape lines suggested that the cleistogamous trait is controlled by at least two genes ( $\mathrm{Clg} 1$ and $\mathrm{Clg} 2)$ with an epistatic dominant effect of $\mathrm{Clg} 1$ over $\mathrm{Clg} 2$ (Lu et al., 2008). Leflon et al. (2009b) examined the reliability of the cleistogamous trait for two inbred oilseed rape lines in field trials. The flower opening level was measured at different dates during the flowering period in six field experiments (three sites $\times$ two years). The results showed a line with promising stability and a line with highly unstable behaviour. Some flowers were partially opened with rates varying from 0.5 to $33 \%$ depending on genotypes, trials (site and year) and recording dates. Leflon et al. (2009a, 2009b) considered that, even when partially unstable, CL could be beneficially used in combination with other means in a containment strategy. Despite the fact that cleistogamous lines are stably expressed under various environmental and agricultural conditions and show high heritability, it is also important to investigate the autogamy rates of cleistogamous lines in order to ensure the purity of any "specialty" crop. In another study the rate of allopollination in cleistogamous lines under several environmental conditions was assessed (Leflon et al., 2009a). Although differences among sites and years were observed, average allogamy rates of cleistogamous lines grown under a high pressure of allopollen varied in three locations between 4.4 and $16.2 \%$. Conventional oilseed rape also shows a considerable degree of receptiveness to pollen from other varieties. These estimates range from 12 to and 55\%, averaging 30\% (Hüsken and Dietz-Pfeilstetter, 2007). In samples collected from open pollinated cleistogamous plants at $0 \mathrm{~m}$ from the pollen source the percentage allogamy rate was $1.64 \%$ and it was $0.26 \%$ at $6 \mathrm{~m}$ distance. Allo-pollination may occur at larger distances to the pollen source, although at levels $<0.2 \%$. These data suggest that cleistogamy could be a promising strategy for transgene containment in autogamous crops, however in the case of instabilities, data about the actual amount of pollen dispersal or the frequency of transgene transmission are still lacking.

\section{Cytoplasmic male sterility}

Cytoplasmic male sterility (CMS) is a naturally occurring and maternally transmitted trait, whereby a plant is unable to produce viable pollen. CMS results from gain-of-function mutations in the plant mitochondrial genome (Chase and Gabay-Laughnan, 2004), responsible for a dysfunction in the respiratory metabolism which can lead to deleterious phenotypes (Chase, 2007; Cilier et al., 2004), resulting in the abnormal production of male gametes (Budar et al., 2003). Therefore, plants either produce no pollen or pollen that is not viable. However, female fertility is not affected by CMS. Kriete et al. (1996) reported naturally occurring CMS for maize, oilseed rape, rice, and Beta beets. CMS inbred lines have been widely used for hybrid seed production of many crops (Chase, 2006; Havey, 2004; Pelletier and Budar, 2007; Perez-Prat and van Lockeren Campagne, 2002). Reports on the stability of CMS indicated that there is a high variability for different genotypes under different environmental conditions and over successive years. This was observed in cotton (Marshall et al., 1974; Sarvella, 1966), oilseed rape (Fan and Stefansson, 1986) and onion (Peterson and Foskett, 1953). Temperature, photoperiod and water availability are described as factors that can influence the stability of male sterility. It is generally agreed that sterility increases with increasing temperature and day length (Latha et al., 2004; Marshall et al., 1974; Sawhney, 2004). Stamp et al. (2000) suggested that this trait could be an important tool for enabling efficient and reliable coexistence between GM and non-GM cultivation by biocontainment of GM maize pollen. In this context, Weider et al. (2009) investigated the stability of the cytoplasmic male sterility trait of 22 CMS versions of modern European maize hybrids in 17 different environments in Europe over two years. Of the three types of male-sterile cytoplasm (T-, S- and C-type), the sterility of the T- and C-cytoplasm hybrids was most stable. S-cytoplasm hybrids often showed partial restoration of fertility. Of the eight C-cytoplasm hybrids tested in the study, five were fully sterile. Of the eight T-cytoplasm hybrids also five were fully sterile across all environments. The genetic instability of S-cytoplasm, coupled with its sensitivity to environmental conditions makes the $\mathrm{S}$ system generally unreliable for hybrid seed production and biocontainment. Climatic factors, especially air temperature, humidity and evapotranspiration in the ten days before as well as during anthesis, were correlated positively or negatively with the partial reversion of male fertility. $\mathrm{T}$ - and C-cytoplasm sterile maize hybrids show viable prospects for containing transgenic pollen (Weider et al., 2009). CMS T was identified as the most stable type of male sterile cytoplasm; nevertheless, due to its susceptibility to the fungi Bipolaris maydis, its use may be limited to the growth of small scale transgenic fields, e.g. molecular farming. To achieve a useful agricultural biocontainment system sowing a mixture of GM CMS-maize hybrid $(80 \%)$ and an unrelated conventional fertile hybrid (20\%) is recommended, whereby the latter component acts as 
pollen donor for the entire stand. In this Plus-Hybrid System pollination of the crop is ensured while the release of GM pollen is minimised (Munsch et al., 2008). In addition, appropriate combinations of CMS hybrids and fertile pollinators could lead to a significant gain in yield (Munsch et al., 2010; Stamp et al., 2000; Weingartner et al., 2002), due to combining potential benefits of male sterility (CMS effect) and allopollination (xenia effect).

In sunflower, the use of CMS could also serve as an alternative route to prevent transgene escape. In a 3-years study in different locations in Bulgaria, six CMS sunflower lines were evaluated concerning the stability of the CMS trait (Hvarleva et al., 2009). Four lines were fully sterile across all environmental conditions, while two lines showed unstable sterility. The data suggest that the climatic conditions may affect the stability of sterility depending on their genotype.

In summary, we expect that CMS can provide a powerful tool to manage gene flow issues by eliminating or reducing the release of pollen. However there is instability in these systems and data about the actual amount of pollen dispersal or the frequency of transgene transmission, at field scales of production, are still lacking.

\section{CONCLUSION}

Despite the great progress that has been made in the development of approaches to reduce or prevent transgene flow through pollen, the biological containment strategies discussed here all show the tendancy of not being completely effective. In addition, data about the actual amount of transgene pollen dispersal or the frequency of transgene transmission at the field level are still lacking. However, there might be tolerance of incomplete biocontainment, depending on the trait/plant combination under consideration. Biological containment methods can be used in combination and also combined with physical containment methods, such as wide distances between donor and recipient fields as barriers for pollen flow, in order to further reduce frequencies of pollen transmission. In cases where pollen transmission must be prevented altogether, more research is required to determine effective combinations of the different containment methods required to achieve this.

\section{ACKNOWLEDGEMENTS}

We thank Ulrich Thewes for his great scientific support and the referees for their helpful suggestions. Gratitude is expressed to the Federal Ministry of Education and Research (BMBF) which provided financial support to one of the authors (S.P.) through the project "Research on Biological Safety of Genetically Modified Plants" (Funding code $0315210 \mathrm{D})$.

Received September 10, 2010; accepted November 11, 2010.

\section{REFERENCES}

Allainguillaume J, Harwood T, Ford CS, Cuccato G, Norris C, Allender CJ, Welters R, King GJ, Wilkinson MJ (2009) Rapeseed cytoplasm gives advantage in wild relatives and complicates genetically modified crop biocontainment. New Phytol. 183: 1201-1211

Avni A, Edelmann M (1991) Direct selection for paternal inheritance of chloroplasts in sexual progeny of Nicotiana. Mol. Gen. Genet. 225: 273-277

Azhagiri AK, Maliga P (2007) Exceptional paternal inheritance of plastids in Arabidopsis suggests that low-frequency leakage of plastids via pollen may be universal in plants. Plant J. 52: 817-823

Benitez ER, Khan NA, Matsumura H, Abe J, Takahas R (2010) Varietal differences and morphology of cleistogamy in soybean. Crop Sci. 50: 185-190

Birky CW (1995) Uniparental inheritance of mitochondrial and chloroplast genes: Mechanisms and evolution. Proc. Natl. Acad. Sci. USA 92: 11331-11338

Bock R, Khan MS (2004) Taming plastids for a green future. Trends Biotechnol. 22: 311-318

Bock R, Timmis JN (2008) Reconstructing evolution: gene transfer from plastids to the nucleus. Bioassays 30: 556-566

Budar F, Touzet P, De Paepe R (2003) The nucleomitochondrial conflict in cytoplasmic male sterilities revisited. Genetica 117: 3-16

Chase CD (2006) Genetically engineered cytoplasmic male sterility. Trends Plant Sci. 11: 7-9

Chase CD (2007) Cytoplasmic male sterility: a window to the world of plantmitochon-drial-nuclear interaction. Trends Genet. 23: 81-90

Chase CD, Gabay-Laughnan S (2004) Cytoplasmic male sterility and fertility restoration by nuclear genes. In Daniell H, Chase CD, eds, Molecular Biology and Biotechnology of Plant Organelles, Springer, New York, pp 593-622

Cilier M, Feruzan D, Göksel O (2004) Histological aspects of anther wall in male fertile and cytoplasmic male sterile Helianthus annuus L. Asi. J. Plant Sci. 3: 145-150

Connor HE (1979) Breeding systems in the grasses: a survey. New Zealand Journal of Botany 17: 547-574

Conner AJ, Glare TR, Nap JP (2003) The release of genetically modified crops into the environment - Part II. Overview of ecological risk assessment. Plant J. 33: 19-46

Cummins JE (1998) Chloroplast-transgenic plants are not a gene flow panacea. Nat. Biotechnol. 16: 401

Daniell H (2002) Molecular strategies for gene containment in transgenic crops. Nat. Biotechnol. 20: 581-586 
Daniell H, Kumar S, Dufourmantel N (2005) Breakthrough in chloroplast genetic engineering of agronomically important crops. Trends Biotechnol. 23: 238-245

De Maagd RA, Boutilier K (2009) Efficacy of strategies for biological containment of transgenic crops. A literature review. Plant Research International, Note 650

DeCosa B, Moar W, Lee SB, Miller M, Daniell H (2001) Overexpression of the $B t$ cry2Aa2 operon in chloroplasts leads to formation of insecticidal crystals. Nat. Biotechnol. 19: $71-74$

Den Nijs HCM, Bartsch D, Sweet J (eds) (2004) Introgression from genetically modified plants into wild relatives. $C A B I$, p 432

Derepas A, Dulieu H (1992) Inheritance of the capacity to transfer plastids by the pollen parent in Petunia hybrida hort. Heredity 83: 6-10

Diaz A, MacNair MR (1998) The effect of plant size on the expression of cleistogamy in Mimulus nasutus. Funct. Ecol. 12: $92-98$

Dong J, Wagner DB (1994) Paternally inherited chloroplast polymorphism in Pinus: estimation of diversity and population subdivision, and tests of disequilibrium with maternally inherited mitochondrial polymorphism. Genetics 136: 11871194

Dunwell JC, Ford CS (2005) Technologies for biological containment of GM- and non-GM-crops. Final Report, Defra Contract CBEC 47

EFSA (2009) Scientific opinion on guidance for the risk assessment of genetically modified plants used for non-food or non-feed purposes. EFSA Journal 1164: 1-42

Fan ZG, Stefansson BR (1986) Influence of temperature on sterility of 2 cytoplasmic male-sterility systems in rape (Brassica napus L.). Can J. Plant Sci. 66: 221-227

Gealy DR (2005) Gene movement between rice (Oryza sativa) and weedy rice (Oryza sativa): a U.S. temperate rice perspective. In Gressel J., ed, Crop Ferality and Volunteerism, CRC Press

Gidoni D, Srivastava V, Carmi N (2008) Site-specific excisional recombination strategies for elimination of undesirable transgenes from crop plants. In Vitro Cell Dev. Biol. - Plant 44: $457-467$

Gressel J, Al-Ahmad H (2005) Assessing and managing biological risks of plants used for bioremediation, including risks of transgene flow. Z. Nat. forsch. 60c: 154-165

Gressel J, Valverde BE (2009) A strategy to provide long-term control of weedy rice while mitigating herbicide resistance transgene flow, and its potential use for other crops with related weeds. Pest. Manag. Sci. 65: 723-731

Grevich JJ, Daniell H (2005) Chloroplast genetic engineering: Recent advances and future perspectives. Crit. Rev. Plant Sci. 24: $83-107$

Havey M (2004) The use of cytoplasmic male-sterility in hybrid seed production. In Daniell H, Chase C, eds, Molecular Biology and Biotechnology of Plant Organelles, Springer, New York, pp 623-634

Haygood RA, Ives AR, Andow DA (2004) Population genetics of transgene containment. Ecol. Lett. 7: 213-220
Hoshikawa K (1993) Anthesis, fertilization and development of caryopsis. In Matsuo T, Hoshikawa K, eds, Science of the rice plant, vol. 1 (Morphology), Food and Agriculture Policy Research Center, Nobunkyo Publ. Co, Tokyo, pp 339-376

Hüsken A, Dietz-Pfeilstetter A (2007) Pollen-mediated gene flow from herbicide-resistant oilseed rape (Brassica napus L.). Trans. Res. 16: 557-569

Hvarleva T, Hristova M, Bakalova A, Hristov M, Atanossov I, Atanassov A (2009) CMS lines for evaluation of pollen flow in sunflower relevance for transgene flow mitigation. Biotechnol. Biotechnol. Equip. 23: 1309-1315

Kriete G, Niehaus K, Perlick AM, Puhler A, Broer I (1996) Male sterility in transgenic tobacco plants induced by tapetum-specific deacetylation of the externally applied non-toxic compound N-acetyl-L-phosphinothricin. Plant J. 9: 809-818

Kuraichi N, Makino T, Hirose S (1994) Inheritance of cleistogamy-chasmogamy in barley. Barley Genet. Newsl. 23: 19

Latha R, Thiyagarajan K, Senthilvel S (2004) Genetics, fertility behavior and molecular marker analysis of a new TGMS line, TS6, in rice. Plant Breed. 123: 235-240

Leflon M, Pinochet X, Hüsken A, Pendergast D, Knightly S (2009a) Cleistogamy of oilseed rape: a way to prevent pollen flow at the field scale? In 5th ISHS International Symposium on Brassicas, Programme and Abstract Book, Lillehammer, Norway

Leflon M, Hüsken A, Njontje C, Knightly S, Pendergast D, Pierre J, Renard M, Pinochet X (2009b) Stability of the cleistogamous trait during the flowering period of oilseed rape. Plant Breed. 129: 13-18

Lu BR (2003) Transgene containment by molecular means - is it possible and cost effective? Environ. Biosafety Res. 2: 3-8

Lu BR (2008) Transgene escape from GM crops and potential biosafety consequences: An anvironmental perspective. Coll. Biosafety Reviews 4: 66-141

Lu YH, Belcram H, Rouault P, Piel N, Lucas MO, Falentin C, Renard M, Chalhoub B, Delourme R (2008) Cloning of a cleistogamy gene $C l g 1$ in oilseed rape (B. napus L). In 5th ISHS International Symposium on Brassicas, Programme and Abstract Book, Lillehammer, Norway

Luo K, Duan H, Zhao D, Zheng X, Deng W, Chen Y, Stewart Jr CN, McAvoy R, Jiang X, Wu Y, He A, Pei Y, Li Y (2007) 'GM-gene-deletor': Fused loxP-FRT recognition sequences dramatically improve the efficiency of FLP or CRE recombinase on transgene excision from pollen and seed of tobacco plants. Plant Biotechnol. J. 5: 263-274

Marshall DR, Thomson NJ, Nichols GH, Patrick CM (1974) Effects of temperature and day length on cytoplasmic male sterility in Cotton (Gossypium). Aust. J. Agric. Res. 25: 443450

Medgyesy P, Menczel L, Maliga P (1980) The use of cytoplasmic streptomycin resistance: chloroplast transfer from Nicotiana tabacum into Nicotiana sylvestris, and isolation of their somatic hybrids. Mol. Gen. Genet. 179: 693-698 
Medgyesy P, Páy A, Márton L (1986) Transmission of paternal chloroplasts in Nicotiana. Mol. Gen. Genet. 204: 195-198

Miyashita K, Matsuda H, Ohara M, Misawa T, Shimamoto Y (1999) Flowering and fruiting dynamics of chasmogamous and cleistogamous flowers in wild and cultivated soybeans. Res. Bul. Univ. Farm 31: 41-48

Mlynárová L, Conner A, Nap JP (2006) Directed microsporespecific recombination of transgenic alleles to prevent pollenmediated transmission of transgenes. Plant Biotechnol. J. 4: 445-452

Munsch M, Camp KH, Stamp P, Weider C (2008) Modern maize hybrids can improve grain yield as plus-hybrids by the combined effects of cytoplasmic male sterility and allopollination. Maydica 53: 262-268

Munsch M, Stamp P, Christov NK, Foueillassar XM, Hüsken A, Camp KH, Weider C (2010) Grain yield increase and pollen containment by Plus-Hybrids could improve acceptance of transgenic maize. Crop Sci. 50: 909-919

Murphy DJ (2007) Improving containment strategies in biopharming. Plant Biotechnol J. 5: 555-569

Nagao S, Takahashi M (1963) Trial construction of twelve linkage groups in Japanese rice. Genetical studies on rice plants. J. Fac. Agr. Hokkaido Univ. 53: 72-130

Pelletier G, Budar F (2007) The molecular biology of cytoplasmically inherited male sterility and prospects for its engineering. Curr. Opin. Biotechnol. 18: 121-125

Perez-Prat E, van Lockeren Campagne MM (2002) Hybrid seed production and the challenge of propagating male-sterile plants. Trends Plant Sci. 7: 199-203

Peterson CE, Foskett RL (1953) Occurrence of pollen sterility in seed fields of Scott County Globe onions. Proc. Am. Soc. Hort. Sci. 62: 443-448

Peterson G, Cunningham S, Deutsch L, Erikson J, Quinlan A, Raez-Luna E, Tinch R, Troell M, Woodburg P, Zens S (2000) The risks and benefits of genetically modified crops: a multidisciplinary perspective. Conserv. Ecol. 4: 13

Quesada-Vargas T, Ruiz ON, Daniell H (2005) Characterization of heterologous multigene operons in transgenic chloroplasts. Plant Physiol. 138: 1746-1762

Ruf S, Karcher D, Bock R (2007) Determining the transgene containment level provided by chloroplast transformation. Proc. Natl. Acad. Sci. USA 104: 6998-7002
Ruiz O, Daniell H (2005) Cytoplasmic male sterility engineered via the plastid genome. Plant Physiol. 138: 1232-1246

Sarvella P (1966) Environmental influences on sterility in cytoplasmic male-sterile cottons. Crop Sci. 6: 361-364

Sawhney VK (2004) Photoperiod-sensitive male sterile mutant in tomato and its potential use in hybrid seed production. $J$. Hortic. Sci. Biotech. 79: 138-141

Sheppard AE, Ayliffe MA, Blatch L, Day A, Delaney SK, Khairul-Fahmy N, Li Y, Madesis P, Pryor AJ, Timmis JN (2008) Transfer of plastid DNA to the nucleus is elevated during male gametogenesis in tobacco. Plant Phys. 148: 328-336

Stamp P, Chowchong S, Menzi M, Weingartner U, Kaeser O (2000) Increase in the yield of cytoplasmic male sterile maize revisited. Crop Sci. 40: 1586-1587

Stegemann S, Bock R (2006) Experimental reconstruction of functional gene transfer from the tobacco plastid genome to the nucleus. Plant Cell 18: 2869-2878

Svab Z, Maliga P (2007) Exceptional transmission of plastids and mitochondria from the transplastomic pollen parent and its impact on transgene containment. Proc. Natl. Acad. Sci. USA 104: 7003-7008

Testolin R, Cipriani G (1997) Paternal inheritance of chloroplast DNA and maternal inheritance of mitochondrial DNA in the genus Actinidia. Theor. Appl. Genet. 94: 897-903

Turuspekov Y, Honda I, Watanabe Y, Stein N, Komatsuda T (2009) An inverted and micro-colinear genomic regions of rice and barley carrying the clyl gene for cleistogamy. Breed. Science 59: 657-663

Wang T, Li Y, Shi Y, Reboud X, Darmency H, Gressel J (2004) Low frequency transmission of a plastid-encoded trait in Setaria italica. Theor. Appl. Genet. 108: 315-320

Weingartner U, Kaeser O, Long M, Stamp P (2002) Combining cytoplasmic male sterility and xenia increases grain yield of maize hybrids. Crop Sci. 42: 1848-1856

Weider C, Stamp P, Christov N, Hüsken A, Foueillassar X, Camp KH, Munsch M (2009) Stability of cytoplasmic male sterility in maize under different environmental conditions. Crop Sci. 49: 77-84

Yoshida G, Itoh JI, Ohmori S, Miyoshi K, Horigome A, Uchida E, Kimizu M, Matsumura Y, Kusaba M, Satoh H, Nagato Y (2007) Superwoman1-cleistogamy, a hopeful allele for gene containment in GM-rice. Plant Biotechnol. J. 5: 1-12 